\title{
Assessment of an Online Education System - Comparing Two Theoretical Models
}

\author{
Raafat George Saadé, Fassil Nebebe, and Tak Mak \\ John Molson School of Business, \\ Montreal, Quebec, Canada
}

\section{raafat.saade@gmail.com; fnebebe@jmsb.concordia.ca; tmak@jmsb.concordia.ca}

\begin{abstract}
The intricate construction of online educational systems lies within three principal activities: Design, implementation and proper post-implementation assessment. There is not enough knowledge or experience in those regards. Efficient execution of these three major activities necessitates the use of design and pedagogical models to achieve cost and time efficiency, as well as high pedagogical quality. Utilization of online educational systems would benefit from a structured approach to design, implementation, and student's assessment. In this paper, we present the design of an online education system and its implementation, and we analyze student's behavior towards the system using the theory of planned behavior and the technology acceptance model. A survey methodology approach was followed. The partial least squares method was used for the assessment of the results discussed. Structural equation analysis provides evidence for the superiority of the theory of planned behavior in explaining student's behavior towards online educational systems. Limitation, implications, design recommendations, and suggestions for future research are discussed.
\end{abstract}

Keywords: Theory of planned behavior, Technology acceptance model, Design, Implementation, Online education systems, elearning

\section{Introduction}

Online instruction is a relatively new phenomenon for most faculty members, such that few consider themselves as experts in the field (Sunal et al., 2003). Most of the research today report on differences between face-to-face and online teaching, and new student experiences in online learning. Other concerns being explored are student achievement and attitudes, course design and delivery, course evaluation and instructor behaviors and attitudes. Evaluation of these factors utilizing well-developed research methodologies are few (Sunal et al., 2003) and there is a great need to not only investigate these factors but also evaluate them based on strong theoretical basis. In

Material published as part of this publication, either on-line or in print, is copyrighted by the Informing Science Institute. Permission to make digital or paper copy of part or all of these works for personal or classroom use is granted without fee provided that the copies are not made or distributed for profit or commercial advantage AND that copies 1) bear this notice in full and 2) give the full citation on the first page. It is permissible to abstract these works so long as credit is given. To copy in all other cases or to republish or to post on a server or to redistribute to lists requires specific permission and payment of a fee. Contact Publisher@InformingScience.org to request redistribution permission. this study, we view the course content as knowledge that the instructor holds and the online educational system (OES) as the information system that contains this knowledge as well as the process of delivering it to the students.

Knowledge management entails a structured approach to making it explicit and sharable in a specific context in a specific community, accomplished in sev- 
eral ways with or without information technology (Avdic 2002). Using information technology for knowledge management does not guarantee improved performance (Nissen et al. 2000). An online education system (OES) could serve the continuous learning process to acquire and assimilate knowledge and to improve performance. The importance of an OES would be an important tool to disseminate data and communicate information. Meaning and knowledge can be created in a learning process supported by the OES. Previous works have noted that in the knowledge environment, cognition, constructivism and the social nature are major drivers for the creation of new knowledge (Hood 2002).

Based on a knowledge management perspective, the contribution of this paper is leveraging information and software systems engineering techniques and their combination with sound educational principles and theoretically based assessment method to explain online learning. The paper concludes with a discussion and insights based on 8 years of experiences.

\section{Theoretical Background}

As the higher education industry continues its attempts to develop, integrate, and increase participation in fully online courses, the pressure to study the efficiency of using OESs and its impact on learning increases as well. Although the body of literature is large and growing, the subset of literature dealing with student attitudes towards technology of online computer mediated learning is small (Valenta et al. 2001, Saade and Bahli, 2005, Saade, 2007). The theory of planned behavior (TPB) (Ajzen, 1985) and the technology acceptance model (TAM) can be used to explain behavior towards OESs. The historical antecedent of the TPB and TAM lies in the theory of reasoned action (Fishbein and Azjen 1975).

Within the context of the present work, the TPB presented in figure 1 shows that behavioral intentions to use an online educational system are guided by: (1) the individuals' favorable/unfavorable attitude towards an OES; (2) subjective norm (which can be viewed as social pressure); and (3) perceived behavioral control (which entails the beliefs about the presence of factors that may facilitate/impede performance of the behavior).

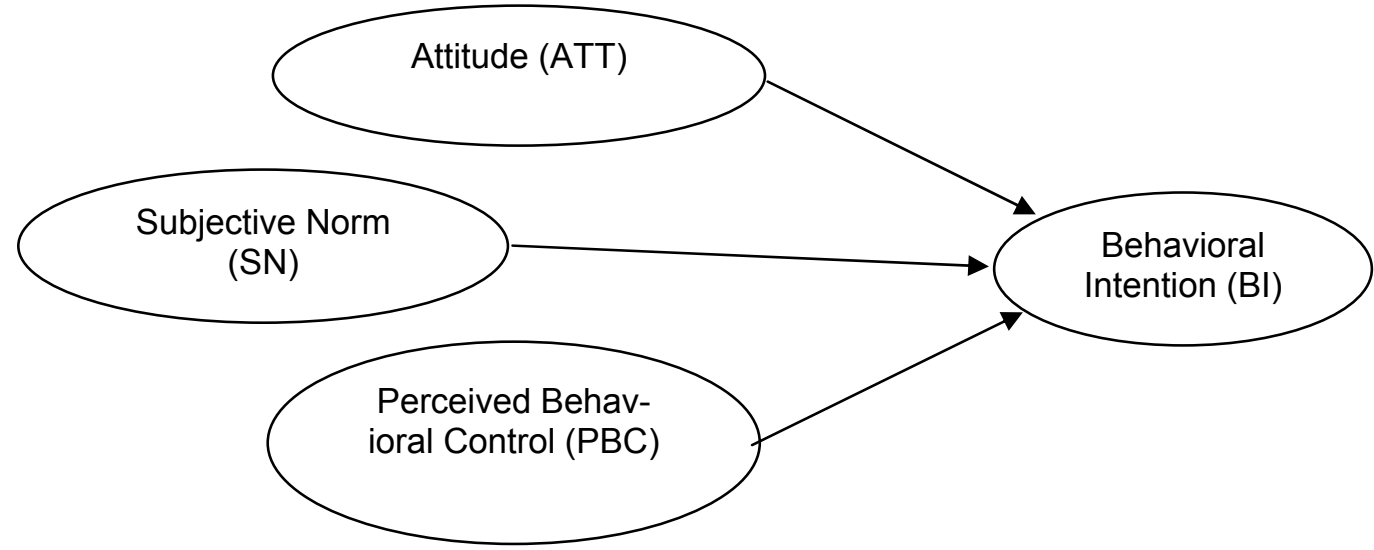

Figure 1. The Theory of Planned Behavior

Studying the acceptance of information technology, (IT) has been the focus of many Information System (IS) researchers. The research efforts have been in the building of theories that can predict the determinant factors of IT acceptance (Lee et al., 2001). The TAM developed by Davis et al. 
(1989) and shown in figure 2 is the most widely used model for IT acceptance and adoption and has received considerable attention in IS research.

The TAM presented in figure 2 (Davis, 1986, 1989) identifies four variables and the relationships between them.

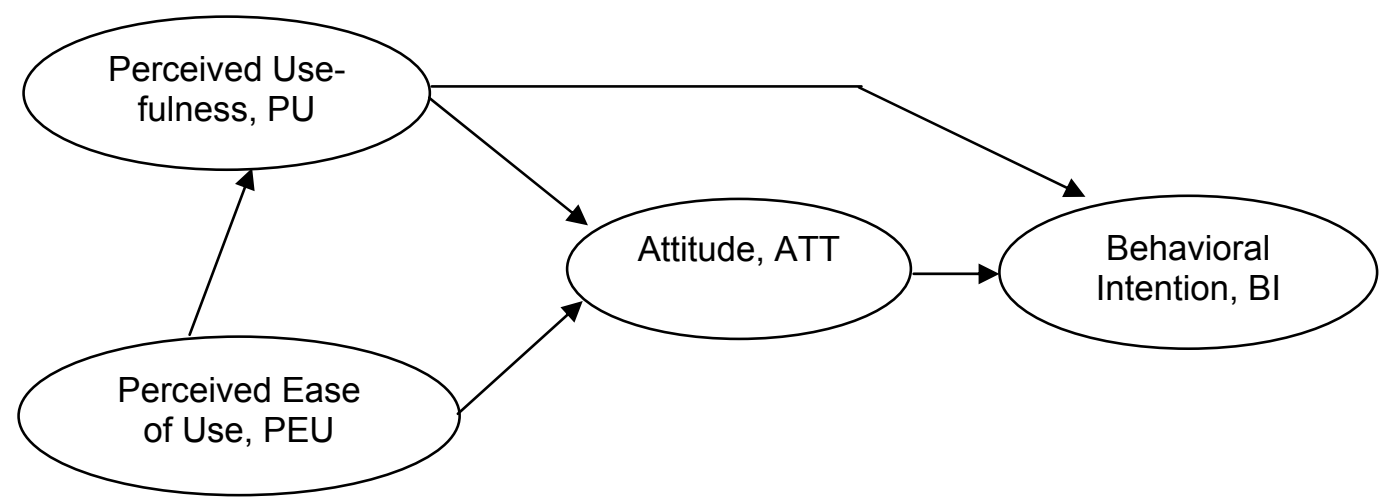

Figure 2. The Technology Acceptance Model

Perceived usefulness is defined as "the degree to which a person believes that using a particular system would enhance his or her job performance" (Davis 1989). Perceived ease of use can be described as "the degree to which a person believes that using a particular system would be free of effort" (Davis 1989). Attitude has been identified as an essential intention determinant to behavioral intention, as described by the well established TRA.

In the TAM, perceived ease of use may influence behavioral intention directly and indirectly via perceived usefulness. This indirect causal effect is justified arguing that by having lower cognitive burden (implying that the system is more easy to use, hence less effort is required to execute tasks) while using the system, more of the cognitive resources are then made available to attention.

Perceived usefulness is influenced by perceived ease of use, such that both constructs are in turn influenced by external variables. These external variables may include system features, training, documentation and user support (Chau 1996, Davis et al. 1989).

\section{Design of the Online Educational System}

Retalis and Avgeriou (2002) explain that the underlying idea of modeling web-based instructional systems is an explicit division of the instructional system into specific subsystems. Following the terminology presented by Retalis and Avgeriou (2002), three constitutive subsystems for effective learning are identified (Retalis \& Avgeriou 2002, Oliver et al. 1996). An architectural blue print is presented in Figure 3: The human subsystem, the resources subsystem, and the implementation subsystem. 


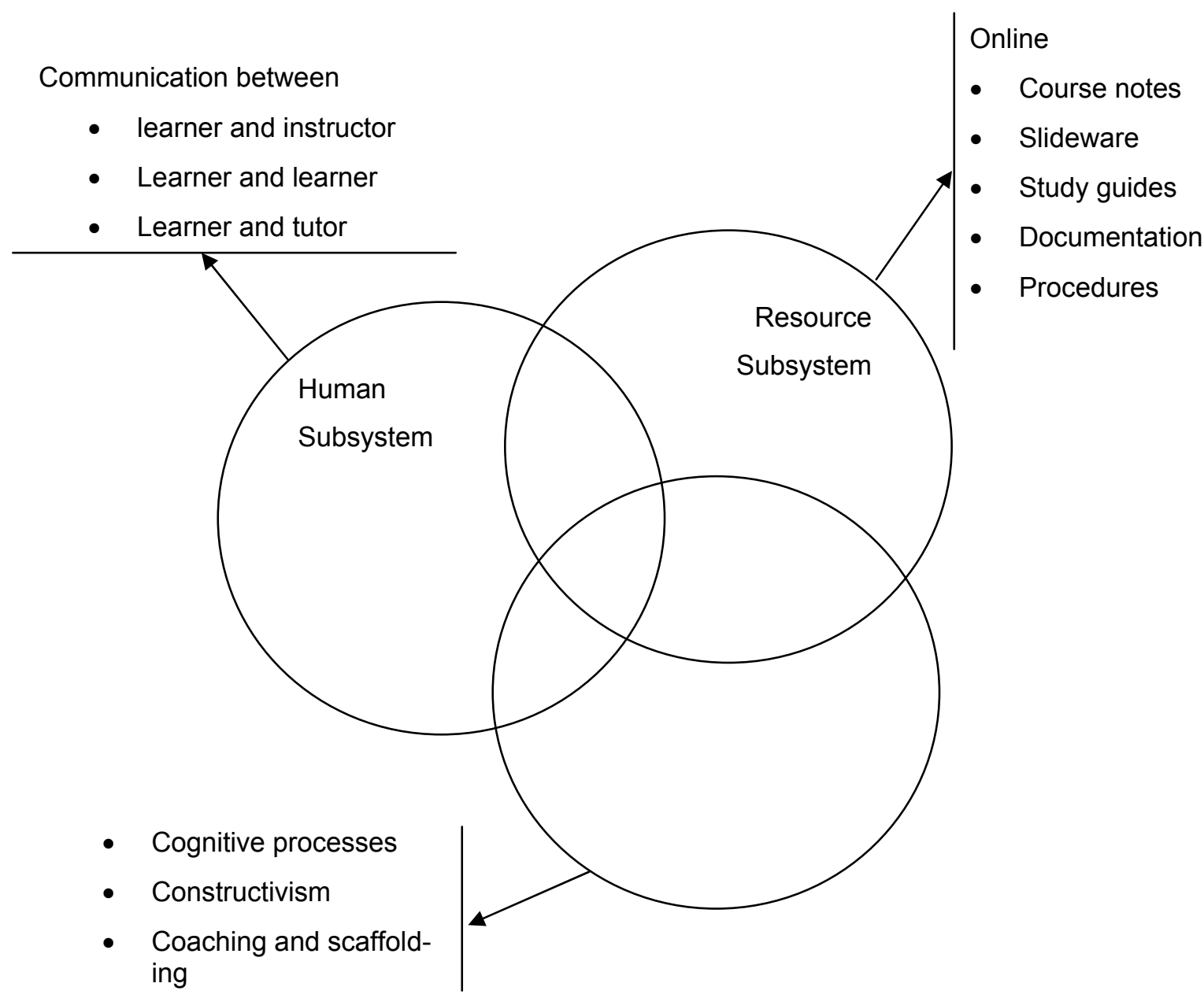

Figure 3. Online Educational Subsystems.

The human subsystem includes the learner and the instructor and responds to their individual and respective needs. The roles of each human agent involved in the instructional process are described (Lindner 2001). The resources subsystem includes online (such as course notes, presentations and other documentation) and non-online material (such as textbooks and CD ROMs). The implementation subsystem entails the use of pedagogical and instructional strategies supporting learning.

\section{The Human Subsystem}

The human agents and their roles are shown in Figure 3. The OES does not entail any physical classes. However, there are tutorials given by a tutor to help students enhance their productivity skills. This includes learning how to use different desktop software such as MS Access and learning basic html.

\section{The Resources Subsystem}

The resources subsystem includes what is referred to sometimes as white pages. These white pages may address the following issues: 
- Additional notes on topics

- Procedures

- Slide presentation

- Course outline

- Links to other online resources

\section{The Implementation Subsystem}

The implementation subsystem entails the use of pedagogical and instructional strategies supporting learning. To that effect, the implementation subsystem is primarily concerned with processes. More specifically, is to answer the question on how the knowledge contained in the subsystems used effectively to actually achieve learning. This knowledge includes:

- The instructors expertise of

○ The content

- The subject matter

$\circ$ Technology

- Learning theories

- The learner's present knowledge

- The knowledge contained in the documents found in the resources subsystem

- The knowledge contained in the implementation subsystem itself.

\section{Methodology}

\section{Study Context and Participants}

The approach taken to test the relationships implied in the proposed research model and the hypotheses was a case study and where a survey methodology was used for data collection. Participants were students enrolled in an introductory undergraduate management information systems on-line course at Concordia University, John Molson School of Business, department of decision sciences and MIS. The on-line course was developed for the web and students were able to use the learning tool (Saade, 2003) anywhere, anytime. The system provides guidance and monitors students' efforts with respect to three variables: time spent on different parts of the system, chapters-based assessment scores, and participation in concept-based forum

Out of 168 students who registered for the course, 114 completed the survey. Since the survey was on-line, the 114 participants completed the survey within a period of 3 weeks.

\section{Students}

The student's sample represented a group: with an average age close to 24 years and work experience approximately 1year; which claims to be somewhat knowledgeable in computers and rate their experience with at least one Microsoft product as high; and have been using the internet for about one year and uses it around 1.5 hours a day. Therefore, based on the students' experiences with computers we expected that they are likely to possess well-formed beliefs and positive perceptions about information technologies.

\section{Operationalization of Research Variables}

All research variables were measured using a five-point Likert-type scale with anchors from "Strongly disagree" to "Strongly agree." Items used to operationalize the constructs were adopted from different relevant prior research work. In specific items for perceived usefulness and ease of use were adapted from Davis 1989 which were extensively validated. Items for behavioral inten- 
tions were based on Ajzen and Fishbein (1980). Finally, items for subjective norm and perceived behavioral control were adapted from Mathieson, 1991.

\section{Assessment of Measurement Model}

Psychometric properties of the scales are assessed in terms of item loadings, discriminant analysis, and internal consistency. Reliabilities of individual items are assessed by examining the loadings of the items on their respective constructs. These loadings should be higher than 0.5 , following the criterion indicated by (Rivard and Huff, 1988) to indicate that significant variance shared between each item and the construct.

Confirmatory factor analysis results show that all items exhibit high loadings, well above the criteria of 0.5 . Without exceptions, all items load more highly on their own construct than on other constructs. The loadings show a clear discriminant and convergent validity for all constructs. Furthermore, all constructs in the model exhibit good internal consistency as evidenced by the reliability coefficient given in table 7 . The reliability coefficient for internal consistency for the six constructs are more than adequate with values above 0.9 with the exception of intention to use $(0.8)$.

\section{Assessment of Structural Model}

The assessment of the structural model was done using PLS Graph (Chin, 1999). The estimated path effects are given along with their degree of significance. The paths are interpreted as standardized beta weights in a regression analysis. Perceived usefulness and attitude together explain $38 \%$ of intentions, while social norm, perceived behavioral control, and attitude explain $58 \%$. The theory of planned behavior explains intentions around $50 \%$ better. Perceived usefulness and perceived ease of use account for $46 \%$ of the variance in attitude. It is evident from figure 5 that PLS results provide stronger support for the theory of planned behavior than those of the technology acceptance model. 


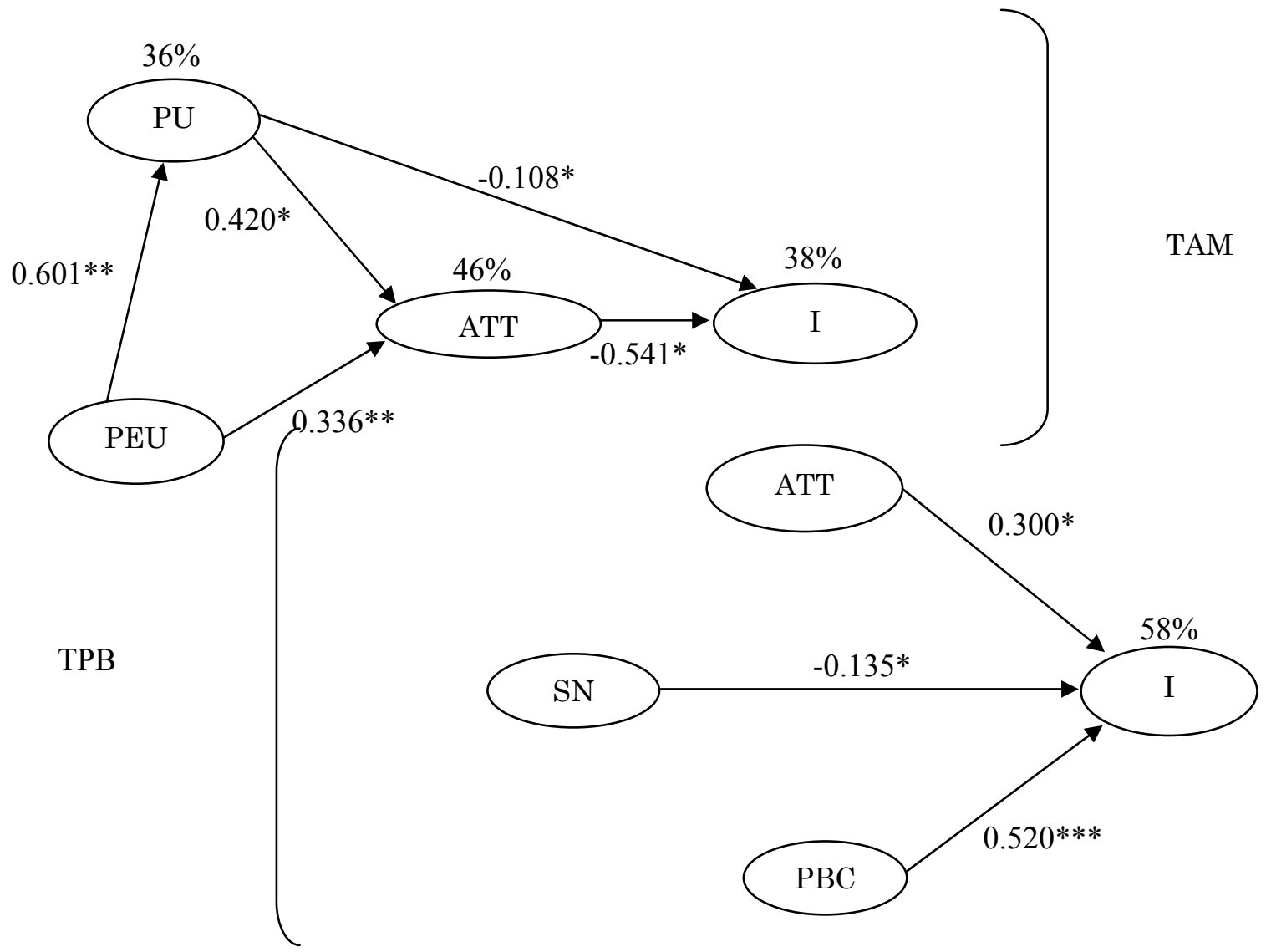

Figure 5: Model parameters for the research model.

\section{Guidelines for OES Designers}

Based on our 14 years of elearning experiences in designing, implementing, maintaining, and evaluating OESs, we list below some basic guidelines, which can be refined, based on the environment and context the online course is being developed.

\section{- Design components}

a. Separate the administrative section of the course from the learning activities of the course.

b. Suggest a few steps where students can follow for their learning process. Those steps do not need to not need to be complex and could be as simple as "look-ListenLearn."

c. Include a forum where students can communicate with each other about anything. This brings students together where they can help each other with course related questions.

\section{- Implementation process}

Once you are in the implementation process, we assume that your course is ready to be utilized via a web browser.

a. You need to create an orientation for the course. Students who missed the orientation session had many more questions later during the session than those who attended.

b. Course content: 
- Include a copy or your notes and presentation in the white pages.

- Try to present the online topics/chapter in chunks of six or seven. Avoid including large files or multimedia that require add-ons.

c. Instructor-student relationship

- The bulletin board is highly effective.

- Email response time is critical. When the response time was long (in terms of days) students perceived that they are less in control with following the course and their attitudes shifted from positive to negative by viewing the course to be more difficult to follow.

- Students do not read. Instructors need to encourage appropriate online expectations. When a student asks a question where the answer is available either in the bulletin board or in the white pages, the instructor should direct the student to where that answer is and not answer the question.

- The instructor can also setup asynchronous virtual office hours. In this case, questions and answers are practically real time.

d. Course management: For an effective online course

- Address students concerns and feedback in the design of the course.

- Solicit students for ways to enhance the course.

- Try to provide documentation that is written as if you are talking to the students. This provides a feeling of conversation and reduces loneliness.

- Provide motivational messages a few times along the session.

- Insist on students coming to the orientation. Not all will be able to come.

\section{Conclusions}

This research was driven by the need to bring together design processes, learning principles and MIS methodology. This structured design-assessment approach is multidisciplinary and not traditionally followed by researchers in the fields of education, engineering and MIS. Acknowledging the fact that the nature of information technologies has changed considerably, we argue that in the case of online learning, we need to focus our attention to a complete and structured learningdesign-assessment approach to development.

Not only does this approach provide a structured framework to design and assess online learning, it also

- Provides controls at different levels to reproduce under experimental setups

- Allows researchers to implement under different contexts hence facilitating the analysis of the mediating effects of the different contexts on student experiences

- Permits the studying of direct and indirect effects of constructs on one another

- Can give tangible and measurable results that may tell the researcher how to modify the design to obtain enhanced student experiences

\section{References}

Ajzen, I. (1985). From intentions to actions: A theory of planned behavior. In J. Kuhl \& J. Beckmann (Eds.), Action control: From cognition to behavior (pp. 11 - 39). Heidelberg: Springer.

Ajzen, I., \& Fishbein, M. (1980). Understanding attitudes and predicting social behavior. Englewood Cliffs, NH: Prentice Hall.

Avdic, A., \& Westin, O. (2002). A local information systems perspective on knowledge management, The Xth European Conference on Information Systems, June. 
Chau, K. Y. P. (1996). An empirical assessment of a modified technology acceptance model. Journal of Management Information Systems, 13(2), 185-204.

Chin, K. L. (1999). A study into students' perceptions of web-based learning environment. HERDSA Annual International Conference, Melbourne, July.

Davis, D. F. (1986). A technology acceptance model for empirically testing new end-user information systems: Theory and results. Doctoral Dissertation, Sloan School of Management, Massachusetts Institute of Technology.

Davis, D. F. (1989). Perceived usefulness, perceived ease of use, and user acceptance of information technology. MIS Quarterly, 13(3), 319-339.

Davis, D. F., Bagozzi, P. R., \& Warshaw, R. P. (1989). User acceptance of computer technology: A comparison of two theoretical models. Management Science, 35(8), 982-1003.

Fishbein, M., \& Ajzen I. (1975). Belief, attitude, intention, and behavior. Reading, MA: AddisionWesley.

Hood, P. (2002). Perspectives on knowledge utilization in education. WestEd.

Lee, D., Park, J., \& Ahn, J. (2001). On the explanation of factors affecting e-commerce adoption. Proceedings of the 22nd International Conference on Information Systems (ICIS 2001), New Orleans, Louisiana, USA, December 16-19, pp.109-120.

Lindner, R. (2001). Expertise and role identification for learning environments (ERILE). Proposed Standard Draft for German DIN NI-36 (planned to be a mirror for the ISO/IEC JTC1 SC36). Retrieved from http://www.igd.fhg.de/ lindner/PROMETEUS/SIG-DESIGN_Meeting-Point.html

Nissen, M., Kamel, M., \& Sengupta, K. (2000). Integrated analysis and design of knowledge systems and processes. Information Resources Management Journal, 13 (1).

Retalis, S., \& Avgeriou, P. (2002). Modelling web-based instructional systems. Journal of Information Technology Education, 1(1), 25-42. Retrieved from http://www.jite.org/documents/Vol1/v1n1p025042.pdf

Rivard, S., \& Huff, S. (1988). Factors for success for end-user computing. Communications of ACM, 31(5), $552-561$.

Saadé, G. R. (2003). Web-based educational information system for enhanced learning, (EISEL): Student assessment. Journal of Information Technology Education, 2, 267-277. Retrieved from http://jite.org/documents/Vol2/v2p267-277-26.pdf

Saadé, G. R. (2007). Dimensions of perceived usefulness: Toward enhanced assessment. Decision Sciences - Journal of Innovation Education, 5(2), 289-310.

Saadé, G. R., \& Bahli, B. (2005). The impact of cognitive absorption on perceived usefulness and perceived ease of use in on-line learning: An extension of the technology acceptance model. Information and Management, 42(2), 317-327.

Sunal, W. D., Sunal, S. C., Odell, R. M., \& Sundberg, A. C. (2003). Research-supported best practices for developing online learning. The Journal of Interactive Online Learning, 2(1), 1-40.

Valenta, A., Therriault, D., Dieter, M., \& Mrtek, R. (2001). Identifying student attitudes and learning styles in distance education. Journal of Asynchronous Learning Networks, 5(2). 


\section{Biographies}

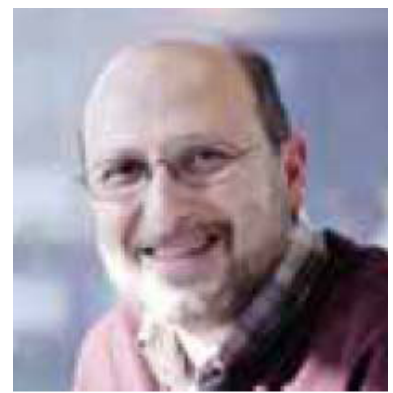

Raafat George Saadé is a lecturer at the Department of Decision Sciences and Management of Information Systems, John Molson School of Business, Concordia University, Montreal Canada. Dr. Saadé received his Ph.D. from Concordia University after which he won the National Science and Engineering Research Council (NSERC) postdoctoral research award (2 years) and which he completed at McGill University. Dr. Saadé has published papers in Information and Management, Expert Systems with Applications, Journal of Asynchronous Learning Networks, Decision Sciences, and others. He is the associate editor of the Journal of Information and Information Technology in Organizations and a member of the Informing Sciences Institute. Dr. Saadé is engaged in three research pipelines: e-Learning, e-Health and Supply Chain of Digital Information Products.

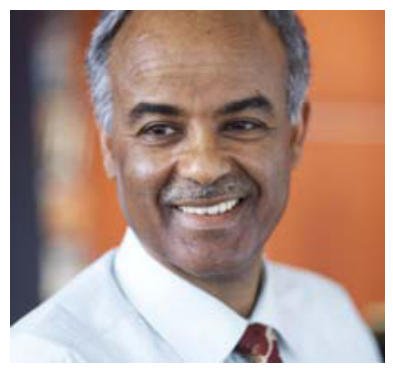

Dr. Fassil Nebebe is a Full Professor at the Department of Decision Sciences \& M.I.S. of the John Molson School of Business, Concordia University, Montreal, Canada. His research interests are in Bayes and empirical Bayes modeling and analysis of data, resampling methods, small area estimation, statistical computing and data mining. He has served as Managing Editor of Liaison - The Newsletter of the Statistical Society of Canada and the President of the Statistical Society of Montreal. He is the founding President of the SSENA, and since 1995 he has been an International Advisory Board member of SINET: Ethiopian Journal of Science, and JESA: Journal of the Ethiopian Statistical Association.

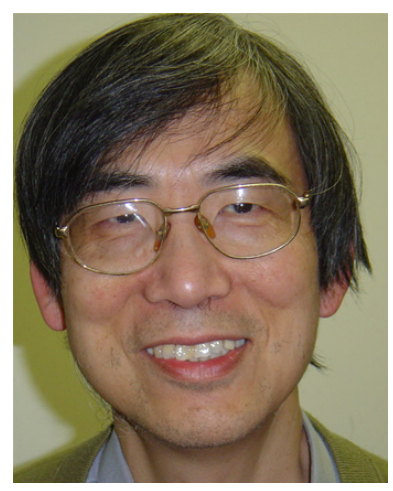

Dr. Tak Mak has been with the Faculty since 1991, Tak Mak obtained his BSc degree in Mathematics from the Chinese University of Hong Kong. He also holds an MA in Mathematics from York University and a $\mathrm{PhD}$ in Statistics from the University of Western Ontario. Prior to joining Concordia University, he taught at the Hong Kong Polytechnic, the University of Hong Kong and the Memorial University of Newfoundland. He teaches statistical models for business research, survey design and analysis, measurement error models and multivariate analysis. His research focuses on statistical methods using the Bootstrap, heteroscedastic regression models, analysis of survey data, statistical quality control. Results published in different areas, including errorsin-variables, interclass and intraclass correlations, ranked data, analyses of misclassified data, regression models, statistical computing, time series analysis, survey sampling, and statistical quality control. He had served as an Associate Editor of the Canadian Journal of Statistics and was an elected member of ISI. He was appointed by NSERC as a committee member of the Statistics Grant Selection Committee for the period September 1994 to May 1997. 